\title{
Evaluation of five regions as DNA barcodes for identification of Lepista species (Tricholomataceae, Basidiomycota) from China
}

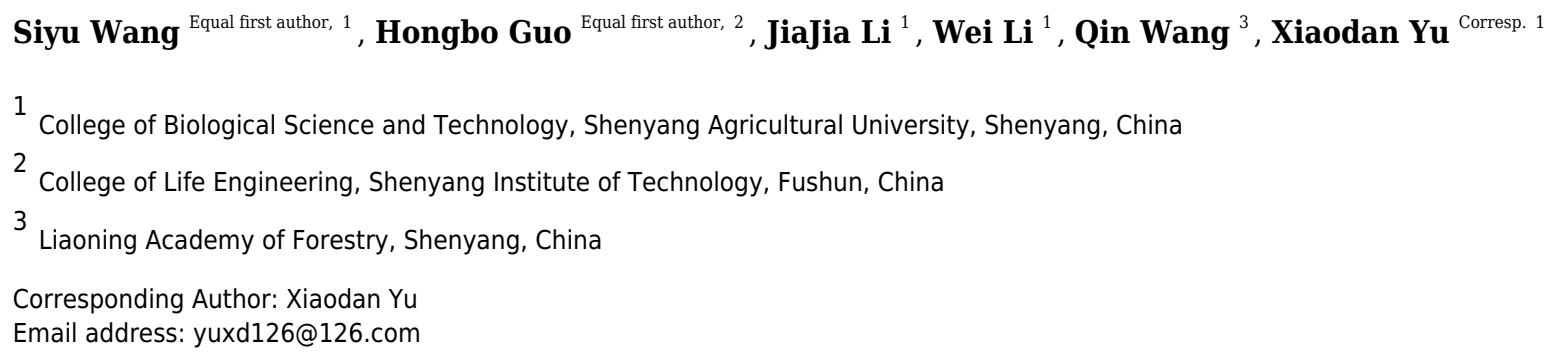

Background. Distinguishing among species in the genus Lepista is difficult because of their similar morphologies. Methods. To identify a suitable DNA barcode for identification of Lepista species, we assessed the following five regions: ITS, IGS, nLSU, mtSSU, and tef1. A total of 134 sequences from 34 samples belong to eight Lepista species were analyzed. The utility of each region as a DNA barcode was assessed based on the success rates of its PCR amplification and sequencing, and on its intra- and inter-specific variations. Results. The results indicated that the ITS region could distinguish all species tested. We therefore propose that the ITS region can be used as a DNA barcode for the genus Lepista. In addition, a phylogenetic tree based on the ITS region showed that the tested eight Lepista species, including two unrecognized species, formed eight separate and well-supported clades. 
1 Evaluation of five regions as DNA barcodes for 2 identification of Lepista species (Tricholomataceae, 3 Basidiomycota) from China

${ }^{1}$ College of Biological Science and Technology, Shenyang Agricultural University, Shenyang, 9 Liaoning, China

${ }^{2}$ College of Life Engineering, Shenyang Institute of Technology, Fushun, China

${ }^{3}$ Liaoning Academy of Forestry, Shenyang, China

Siyu Wang ${ }^{1 \#}$, Hongbo Guo ${ }^{2 \#}$, Jiajia Li ${ }^{1}$, Wei $\mathrm{Li}^{1}$, Qin Wang ${ }^{3}$, Xiaodan $\mathrm{Yu}^{1}$

\section{Corresponding Author:}

Xiaodan $\mathrm{Yu}$

Dongling road 120, Shenyang, Liaoning, 110866, China

Email address: yuxd126@126.com; yuxiaodan@syau.edu.cn

\#These authors contributed equally to this work.

\section{Abstract}

Background. Distinguishing among species in the genus Lepista is difficult because of their similar morphologies.

Methods. To identify a suitable DNA barcode for identification of Lepista species, we assessed the following five regions: ITS, IGS, nLSU, mtSSU, and tef1. A total of 134 sequences from 34 samples belong to eight Lepista species were analyzed. The utility of each region as a DNA barcode was assessed based on the success rates of its PCR amplification and sequencing, and on its intra- and inter-specific variations.

Results. The results indicated that the ITS region could distinguish all species tested. We therefore propose that the ITS region can be used as a DNA barcode for the genus Lepista. In addition, a phylogenetic tree based on the ITS region showed that the tested eight Lepista species, including two unrecognized species, formed eight separate and well-supported clades.

\section{Introduction}

Lepista (Fr.) W.G. Sm., a genus in the family Tricholomataeae, was erected by Smith in 1870 and contains about 50 species (Kirk et al., 2008). Twelve Lepista species have been reported in China 
36

37

38

39

40

41

42

43

44

45

46

47

48

49

50

51

52

53

54

55

56

57

58

59

60

61

62

63

64

65

where they are widely distributed (Mao, 2000; Li et al., 2011). Some Lepista species are popular edible mushrooms in China, and these include Lepista nuda (Bull.) Cooke, L. sordida (Schumach.) Singer, and L. irina (Fr.) H.E. Bigelow (Dai et al., 2010).

The genus Lepista can be distinguished from other genera by the coarse surface of its spores, a white to pale-pink spore print, and clamped hyphae (Singer, 1986; Bon, 1987). Within the genus, however, the limited morphological characteristics make it difficult to distinguish among the species. As a result, misidentification is common both between and within species of Lepista. For example, Lepista irina and L. panaeola have a similar whitish pileus. According to Alvarado et al. (2015), the two species differ in spore size and spore wall structure but the assessment of these characters varies among observers. In addition, other morphological characteristics including the color of the pileus often vary with environmental factors. The pileus of $L$. nuda, for example, was described as grey brown or russet brown in some studies but as purple brown in others (Bon, 1987; Hansen \& Knudsen, 1992).

Accurate identification of species is important for conserving the genetic resources of Lepista, and rapid and reliable species identification is now possible via DNA barcoding. DNA barcoding, which uses short DNA sequences of standard genomic regions, has become increasingly important in identifying species (Badotti et al., 2017; Li et al., 2017) and discovering new species (Zhao et al., 2011; Al-Hatmi et al., 2016). DNA barcoding also could provide the primary information for species delimitation in poorly known groups (Vogler \& Monaghan, 2007) and help identify candidate exemplar taxa for a comprehensive phylogenetic study (Hajibabaei et al., 2007). Based on the requirements for standardized DNA barcoding, the sequences of all candidate markers should be short and should have high rates of successful amplification and high rates of successful sequencing. DNA barcoding also requires that candidate markers have substantial inter-specific variation but not intra-specific variation. The internal transcribed spacer (ITS) region of the nuclear ribosomal RNA gene has been used as a general barcode marker for some groups in the Basidiomycota (Dentinger et al., 2011; Cai et al., 2012; Buyck et al., 2014; Badotti et al., 2017). Other candidate segments that have been used as barcoding markers for mushrooms previously, including the mitochondrial cytochrome oxidase I gene (cox1) (Vialle et al., 2009), the second subunit of RNA polymerase II (RPB2) (Li et al., 2017), and the $\beta$-tubulin and elongation factor 1- $\alpha$ (tef1) (Guo et al., 2016). 
66

67

68

69

70

71

72

73

74

75

76

77

78

79

80

81

82

83

84

85

86

87

88

89

90

91

92

93

94

The goal of the present study was to test the utility of DNA barcodes to the identification of the Lepista species as edible species to address the question, i.e., due to the limited morphological characteristics within the genus Lepista, misidentification often happened. To address the question, we evaluated the following five markers as DNA barcodes for identification of eight Lepista species: Internal transcribed spacer region (ITS), the intergenic spacer (IGS), the large nuclear ribosomal RNA subunit (nLSU), the mitochondrial small subunit rDNA (mtSSU), and tef1.

\section{Materials \& Methods}

\section{Ethics statement}

Lepista species are neither protected nor endangered in the sampled areas, and all samples were collected by researchers following current Chinese regulations. None of the sampled locations are privately owned or protected by law.

9

\section{Sampling}

In a previous study (Alvarado et al., 2015), the genus Lepista was divided into three clades. The current study included two species from each of the three clades plus two unidentified Lepista species. A total of 34 samples of the eight Lepista species were collected from September 2012 to August 2017 (Table 1). Tissue blocks were removed from the inner part of the fresh basidiomata for DNA analyses. The specimens were dried with an electric air ventilation drier and deposited in the Fungal Herbarium of Shenyang Agricultural University (SYAU-FUNGI).

\section{Morphological observations}

Morphological identification was based on previous studies (Singer, 1986; Bon, 1987; Li et al., 2015). Microscopic characteristics of the basidiomata were assessed by examining dried specimens that had been treated with $5 \% \mathrm{KOH}$ solution and Melzer's reagent with a light microscope.

\section{DNA extraction, amplification, and sequencing}


95 Genomic DNA was extracted from fresh blocks of tissue with a plant DNA extraction kit 96 (Sunbiotech, Beijing, China). Crude DNA extracts were used as templates for PCR, and a total of 97 five primers were used for amplification (Table 2). Reaction mixtures were as described by Yu et 98 al. (2014). For the amplification of ITS, IGS, nLSU, and mtSSU, the PCR conditions consisted of 99 an initial denaturation at $94{ }^{\circ} \mathrm{C}$ for $2 \mathrm{~min}$; followed by 30 cycles of denaturation at $94{ }^{\circ} \mathrm{C}$ for $35 \mathrm{~s}$, 100 annealing at $45{ }^{\circ} \mathrm{C}$ for $35 \mathrm{~s}$, and extension at $72{ }^{\circ} \mathrm{C}$ for $1 \mathrm{~min}$; and a final extension at $72{ }^{\circ} \mathrm{C}$ for 10 $101 \mathrm{~min}$. For tef1, the PCR protocol consisted of initial denaturation at $94{ }^{\circ} \mathrm{C}$ for $2 \mathrm{~min}$; followed by 10210 cycles at $94{ }^{\circ} \mathrm{C}$ for $35 \mathrm{~s}, 57^{\circ} \mathrm{C}$ for $35 \mathrm{~s}$ (decreasing $0.3{ }^{\circ} \mathrm{C}$ per cycle), and $72{ }^{\circ} \mathrm{C}$ for $1 \mathrm{~min}$; 103 followed by 29 cycles at $94{ }^{\circ} \mathrm{C}$ for $35 \mathrm{~s}, 54{ }^{\circ} \mathrm{C}$ for $35 \mathrm{~s}$, and $72{ }^{\circ} \mathrm{C}$ for $1 \mathrm{~min}$; and a final extension 104 at $72{ }^{\circ} \mathrm{C}$ for $10 \mathrm{~min}$. PCR products were checked on a $1.0 \%$ agarose gel and visualized by staining 105 with ethidium bromide. Sequencing was performed on an ABI Prism 3730 genetic analyzer (PE 106 Applied Biosystems, Foster City, California, USA). The sequences generated from this study are 107 listed in Table 1.

108

109

\section{Data analyses}

110 Sequences of each region were aligned with Clustal X (Thompson et al., 1997) and then manually 111 edited with BioEdit 5.0.6 (Hall et al., 2003). The aligned sequences of each region were analyzed 112 using DNAstar 7.1.0 (Lasergene, USA) to calculate the similarity matrices. The intra- and inter113 specific variations of the candidate barcode loci for each species were then assessed using 114 TaxonGap 2.4.1(Slabbinck et al., 2008). Finally, the results were processed and showed by 115 GSview 4.9.

116 Genetic pairwise distances for evaluating the sequence variations within and between species 117 of the potential barcode regions were computed using MEGA 7.0 (Kumar et al., 2016) based on the 118 Kimura 2-Parameter (K2P) model (Kimura, 1980). Barcoding gaps comparing the distributions of 119 the pairwise intra- and inter-specific distances for each candidate barcode with distance intervals 120 of 0.004 (ITS, nLSU, and mtSSU) or 0.008 (IGS and tef1) were estimated in Microsoft Excel 2016.

\section{Neighbor-joining tree reconstruction}

123 To show the relationships among the eight Lepista species, a neighbor-joining tree was constructed 124 based on the ITS region using MEGA with the K2P substitution model. Branch support was 125 calculated by a bootstrap analysis with 1000 replicates, and Tricholoma matsutake (AB699640) 
126 was used as the outgroup. For comparison, the combined dataset of five regions was used to 127 construct a neighbor-joining tree. Alignments have been deposited in TreeBASE 128 (http://purl.org/phylo/treebase/phylows/study/TB2:S24378).

129

\section{Results}

\section{PCR amplification and sequencing}

132 A total of 134 sequences of the five candidate DNA barcode regions were obtained from the eight 133 Lepista species (Table 1). The five regions were then evaluated for their potential as barcoding markers (Table 3). Sequence lengths ranged from $400 \mathrm{bp}$ for IGS to $1000 \mathrm{bp}$ for nLSU, i.e., all five regions were sufficiently short to be used as barcode markers. The amplification success rate exceeded $90 \%$ for all regions except tef1, and the sequencing success rate was highest (100\%) for 137 ITS.

138

\section{Intra- and inter-specific variation}

According to TaxonGap analyses of the intra- and inter-specific variations of the candidate DNA barcode regions, ITS, IGS, tefl, and mtSSU provided a somewhat better resolution of the eight species than nLSU. Except for nLSU, the other four regions showed significant inter- and intraspecific variation (Fig. 1).

144

\section{Barcoding gaps}

146 Three regions, i.e., ITS (Fig. 2A), IGS (Fig. 2B), and tef1 (Fig. 2E), had relatively clear barcoding gaps. The two remaining candidate barcodes (mtSSU and nLSU) had overlaps between their intraand inter-specific distances (Fig. 2C, D).

\section{Neighbor-joining analysis}

In a tree generated by a neighbor-joining analysis of the ITS region, the eight species were wellseparated from each other and formed independent terminal branches (Fig. 3). Sequences from sp 1 and $L$. sp 2, were supported by high bootstrap values and were inferred to represent new species of Lepista. The topology of the combined dataset tree was similar to that produced by ITS region (Figure S1). 
157

\section{Discussion}

159 There are two important factors for evaluating candidate DNA barcodes: a high success rate of

160 PCR amplification and sequencing, and substantially greater inter-specific than intra-specific 161 variation. In the current study, the ITS region had high success rates of amplification and 162 sequencing, substantially greater inter-specific than intra-specific variation, as well as clear 163 barcoding gaps among the Lepista species. Based on the criteria, we therefore conclude that the 164 ITS region would be useful for the identification of Lepista species and determine that the ITS is 165 a suitable DNA barcode for the genus Lepista.

The ITS region has been proposed as a universal barcode for fungi (Schoch et al., 2012). The region is present in several chromosomes and is arranged in tandem repeats that are thousands of copies long (Ajmal et al., 2014). Because of the high copy number, the ITS region is easy to amplify and sequence, even with samples from very old specimens (Larsson \& Jacobsson, 2004). ITS has been found to be a suitable barcode for some groups in the Agaricales, including the genus Cortinarius (Liimatainen et al., 2014; Stefani et al., 2014) and the family Lyophyllaceae (Bellanger et al., 2015).

Although IGS had a high PCR success rate (100\%) and suitable inter- and intra- specific variation, its sequencing success rate was relatively low (82\%), which made it the second best marker after ITS for identification of Lepista species. IGS has been previously used to differentiate among species and even among strains within the same species in yeasts (Fell et al., 2000; Scorzetti et al., 2002). In the current study, the regions of nLSU and mtSSU lacked barcoding gaps in the analysis of intra- and inter-specific distance. tefl showed clear barcoding gaps, but its amplification and sequencing success rates were low.

In preliminary studies, we also assessed the largest subunit of RNA polymerase II (RPB1) and RPB2, but we obtained only six sequences of RPB2 and one sequence of RPB1. These numbers of RPB1 and RPB2 sequences were too small for analysis of barcoding, and the two regions were therefore not included in this study.

According to the phylogenetic analysis based on the ITS region, the eight Lepista species received high support ( $\geq 98 \%$ ), which demonstrates that ITS could be used for the identification of Lepista species. The two new clades identified in the present study may represent two new species. Identification of cryptic species by DNA barcoding has been reported in the other groups, such as 
188 Amillariella (Guo et al., 2016) and Pleurotus (Li et al., 2017). In future research, the morphological 189 characteristics of Lepista sp 1 and L. sp 2 should be described, and the utility of ITS as a barcode 190 for identification of additional Lepista species should be evaluated.

191

192

Conclusions

193 In this study, we assessed five regions for identifying a DNA barcode for eight Lepista species. 194 Only the ITS region had the highest success rates of amplification and sequencing, substantially 195 greater inter-specific than intra-specific variation. Therefore, we propose that the ITS region could 196 be used as a suitable DNA barcode for the genus Lepista. And the ITS region also could separate 197 all the tested Lepista species in the phylogenetic analyses. Overall, the ITS region was proved as 198 a reference marker for the other species.

199

\section{Acknowledgements}

201 We thank Prof. Bruce Jaffee for correcting the English.

202

203

204

205

206

207

208

209

210

211

212

213

214

215

216

217

218

\section{References}

Ajmal Ali M, Gyulai G, Hidvégi N, Kerti B, Al Hemaid FMA, Pandey AK, Lee J. 2014. The changing epitome of species identification - DNA barcoding. Saudi Journal of Biological Sciences. 21(3): 204-231. https://doi.org/10.1016/j.sjbs.2014.03.003.

Al-Hatmi AM, Mirabolfathy M, Hagen F, Normand AC, Stielow JB, Karami-Osbo R, van Diepeningen AD, Meis JF, de Hoog GS. 2016. DNA barcoding, MALDI-TOF, and AFLP data support Fusarium ficicrescens as a distinct species within the Fusarium fujikuroi species complex. Fungal Biology. 120(2): 265-278. https://doi.org/10.1016/j.funbio.2015.08.001.

Alvarado P, Moreno G, Vizzini A, Consiglio G, Manjón JL, Setti L. 2015. Atractosporocybe, Leucocybe and Rhizocybe: three new clitocyboid genera in the Tricholomatoid clade (Agaricales) with notes on Clitocybe and Lepista. Mycologia. 107(1): 123-136. https://doi.org/10.3852/13-369.

Badotti F, De Oliveira FS, Garcia CF, Vaz AB, Fonseca PL, Nahum LA, Oliveira G, Góes-Neto A. 2017. Effectiveness of ITS and sub-regions as DNA barcode markers for the identification of Basidiomycota (Fungi). BMC Microbiology. 17(1): 1-12. https://doi.org/10.1186/s12866017-0958-x. 
219 Bellanger JM, Moreau PA, Corriol G, Bidaud A, Chalange R, Dudova Z, Richard F. 2015. 220 Plunging hands into the mushroom jar: a phylogenetic framework for Lyophyllaceae 221 222 (Agaricales, Basidiomycota). Genetica. 143: 169-194. https://doi.org/10.1007/s10709-015-

223 224

225 226

227

228 229 230

231

232

233

234

235

236

237

238

239

240

241

242

243

244

245

246

247

248 9823-8.

Bon M. 1987. The mushrooms and toadstools of Britain and North-western Europe. London (UK): Hodder \& Stoughton.

Buyck B, Kauff F, Eyssartier G, Couloux A, Hofstetter V. 2014. A multilocus phylogeny for worldwide Cantharellus (Cantharellales, Agaricomycetidae). Fungal Divers. 64: 101-121. https://doi.org/10.1007/s13225-013-0272-3.

Cai Q, Tang LP, Yang ZL. 2012. DNA barcoding of eco-nomically important mushrooms: a case study on lethal Amanitas from China. Plant Divers. Resour. 34(6): 614-622. https://doi.org/10.3724/sp.j.1143.2012.12140.

Dai YC, Zhou LW, Yang ZL, Wen HA, Bau T, Li TH. 2010. A revised checklist of edible fungi in China [in Chinese]. Mycosystema. 29:1-21.

Dentinger BTM, Didukh MY, Moncalvo J-M. 2011. Comparing COI and ITS as DNA Barcode Markers for Mushrooms and Allies (Agaricomycotina). PLoS ONE. 6(9): e25081. https://doi.org/10.1371/journal.pone.0025081.

Fell JW, Boekhout T, Fonseca A, Scorzetti G, Statzell-Tallman A. 2000. Biodiversity and systematics of basidiomycetous yeasts as determined by large-subunit rDNA D1/D2 domain sequence analysis. Int. J. Syst. Evol. Microbiol. 50: 1351-1371. https://doi.org/10.1099/00207713-50-3-1351.

Guo T, Wang HC, Xue WQ, Zhao J, Yang ZL. 2016. Phylogenetic analyses of Armillaria reveal at least 15 phylogenetic lineages in China, seven of which are associated with cultivated gastrodia elata. PLoS ONE. 11(5): e0154794. https://doi.org/10.1371/journal.pone.0154794.

Hajibabaei M, Singer GA, Hebert PD, Hickey DA. 2007. DNA barcoding: how it complements taxonomy, molecular phylogenetics and population genetics. Trends Genet. 23(4):167-172. https://doi.org/10.1016/j.tig.2007.02.001.

Hall IR, Stephenson SL, Buchanan PK, Wang Y, Cole ALJ. 2003. Edible and Poisonous Mushrooms of the World. Oregon (USA): Timber Press.

Hansen L, Knudsen H. 1992. Nordic Macromycetes, Vol. 2, Nordsvamp, Copenhagen. 
249 Kimura M. 1980. A simple method for estimating evolutionary rates of base substitutions through 250 comparative studies of nucleotide sequences. J. Mol. Evol. 16: 111-120.

252 253 254

255

256

257

258

259

260

261

262

263

264

265

266

267

268

269

270

271

272

273

274

275

276

277

278 https://doi.org/10.1007/bf01731581.

Kirk PM, Cannon PF, Minter DW, Stalpers JA. 2008. Ainsworth \& Bisby's dictionary of the fungi, 10th ed. Wallingford (UK): CAB International;

Kumar S, Stecher G, Tamura K. 2016. MEGA7: Molecular Evolutionary Genetics Analysis Version 7.0 for Bigger Datasets. Mol Biol Evol. 33(7):1870-1874. https://doi.org/10.1093/molbev/msw054.

Larsson E, Jacobsson S. 2004. Controversy over Hygrophorus cossus settled using ITS sequence data from 200 year-old type material. Mycological Research. 108(7): 781-786. https://doi.org/10.1017/s0953756204000310.

Li J, He X, Liu XB, Yang ZL, Zhao ZW. 2017. Species clarification of oyster mushrooms in China and their DNA barcoding. Mycological Progress. 16(3): 191-203. https://doi.org/10.1007/s11557-016-1266-9.

Li T, Song B, Lin QY, Shen YH, Lin M. 2011. Research on advances of Lepista epiphyte in China. Journal of Anhui Agri Sci; 39(13): 7579-7581, 7770.

Li Y, Li TH, Yang ZL, Tolgor, Dai YC. 2015. Atlas of Chinese Macrofungal Resources. Zhengzhou (China): Central Plains Farmers Press;

Liimatainen K, Niskanen T, Dima B, Kytövuori I, Ammirati JF, Frøslev TG. 2014. The largest type study of Agaricales species to date: Bringing identification and nomenclature of Phlegmacium (Cortinarius) into the DNA era. Persoonia: Molecular Phylogeny and Evolution of Fungi. 33: 98-140. https://doi.org/10.3767/003158514x684681.

Mao XL. 2000. The macrofungi in China [in Chinese]. Zhengzhou (China): Henan Science Technology Press.

Morehouse EA, James TY, Ganley AR, Vilgalys R, Berger L, Murphy PJ, Longcore JE. 2003. Multilocus sequence typing suggests the chytrid pathogen of amphibians is a recently emerged clone. Molecular Ecology. 12(2):395-403.

Rehner SA, Samuels GJ. 1994. Taxonomy and phylogeny of Gliocladium analysed from nuclear large subunit ribosomal DNA sequences. Mycological Research. 98 (6): 625-634. https://doi.org/10.1016/s0953-7562(09)80409-7. 
279 Schoch CL, Seifert KA, Huhndorf S, Robert V, Spouge JL, Levesque CA, Chen W; Fungal 280 Barcoding Consortium; Fungal Barcoding Consortium Author List. 2012. Nuclear ribosomal 281 282 283 284 285 286 287 288 289 290 291 292 293 294 internal tran- scribed spacer (ITS) region as a universal DNA barcode marker for Fungi. Proc. Natl. Acad. Sci. 109: 6241-6246. https://doi.org/10.3410/f.717955047.793460391.

Scorzetti G, Fell JW, Fonseca A, Statzell-Tallman A. 2002. Systematics of basidiomycetous yeasts: a comparison of large subunit D1/D2 and internal transcribed spacer rDNA regions. FEMS Yeast Res. 2: 495-517. https://doi.org/10.1016/s1567-1356(02)00128-9.

Singer R. 1986. The Agaricales in modern taxonomy. 4th ed. Koenigstein (Germany): Koeltz Scientific Books.

Slabbinck B, Dawyndt P, Martens M, De Vos P, De Baets B. 2008. TaxonGap: a visualization tool for intra- and inter-species variation among individual biomarkers. Bioinformatics. 24: 866867. https://doi.org/10.1093/bioinformatics/btn031.

Stefani FOP, Jones RH, May TW. 2014. Concordance of seven gene genealogies compared to phenotypic data reveals multiple cryptic species in Australian dermocyboid Cortinarius (Agaricales). Molecular Phylogenetics and Evolution. 71(1): 249-260. https://doi.org/10.1016/j.ympev.2013.10.019.

Thompson JD, Gibson TJ, Plewniak F, Jeanmougin F, Higgins DG. 1997. The Clustal X windows interface: flexible strategies for multiple sequence alignment aided by quality analysis tools. Nucleic Acids Research. 24: 4876-4882. https://doi.org/10.1093/nar/25.24.4876.

Vialle A, Feau N, Allaire M, Didukh M, Martin F, Moncalvo JM, Hamelin RC. 2009. Evaluation of mitochondrial genes as DNA barcode for Basidiomycota. Mol. Ecol. Resour. 9 (suppl. 1): 99-113. https://doi.org/10.1111/j.1755-0998.2009.02637.x.

Vilgalys R, Hester M. 1990. Rapid genetic identification and mapping of enzymatically amplified ribosomal DNA from several Cryptococcus species. Journal of Bacteriology. 172: 42394246. $\quad$ https://doi.org/10.1128/jb.172.8.4238-4246.1990.

Vogler AP, Monaghan MT. 2007. Recent advances in DNA taxonomy. Journal of Zoological Systematics and Evolutionary Research. 45(1):1-10. https://doi.org/10.1111/j.14390469.2006.00384.x.

White TJ, Bruns T, Lee S, Taylor J. 1990. Amplification and direct sequencing of fungal ribosomal RNA genes from phylogenetics. In: Innes MA, Gelfand DH, Sninsky JS, White TJ (eds), PCR protocols: methods and applications. London (UK): Academic Press; 
310 Yu XD, Lv SX, Ma D, Li FF, Lin Y, Zhang L. 2014. Two new species of Melanoleuca 311 (Agaricales, Basidiomycota) from northeastern China, supported by morphological and 312 molecular data. Mycoscience. 55: 456-461. https://doi.org/10.1016/j.myc.2014.01.007.

313 Zhao P, Luo J, Zhuang W, Liu X, Wu B. 2011. DNA barcoding of the fungal genus Neonectria 314 and the discovery of two new species. Sci China Life Sci. 54(7):664-674. 315 https://doi.org/10.1007/s11427-011-4184-8.

316

317

318

319

320

321

322

323

324

325

326

327

328

329

330

331

332

333

334

335

336

337

338

339

340 


\section{Figure Legends}

342

343 Fig 1. Intra- and inter-specific variations among the candidate barcode regions (ITS, IGS, nLSU,

$344 \mathrm{mtSSU}$, and tef1) from eight Lepista species. Graphs were generated by TaxonGap software. The

345 black and gray bars represent the level of inter- and intra-specific variations, respectively. The thin

346 black lines indicate the lowest inter-specific variation for each candidate barcode. Taxon names

347 next to the dark bars indicate the most closely related species among the species listed on the left.

348 Four regions, i.e., ITS, IGS, tefl, and mtSSU, showed significant inter- and intra-specific variation.

349

350 Fig 2. Frequency distributions of intra- and inter-specific Kimura-2-Parameter pairwise distances 351 among ITS, IGS, nLSU, mtSSU, and tef1 datasets from eight Lepista spp. The black and gray bars 352 represent the level of intra- and inter-specific variations, respectively. Three regions, i.e., ITS, IGS, 353 and tef1, had relatively clear barcoding gaps.

354

355 Fig 3. A neighbor-joining tree generated by analysis of ITS from eight Lepista spp. Bootstrap 356 values $\geqslant 70 \%$ are shown above the relevant branches. The eight Lepista spp. are highlighted in 357 bold.

358

359

360

361

362

363

364

365

366

367

368

369

370

371

372

373

374

375 


\section{Figure $\mathbf{1}$ (on next page)}

Figure 1

Intra- and inter-specific variations among the candidate barcode regions (ITS, IGS, nLSU, mtSSU, and tef1) from eight Lepista species. Graphs were generated by TaxonGap software. The black and gray bars represent the level of inter- and intra-specific variations, respectively. The thin black lines indicate the lowest inter-specific variation for each candidate barcode. Taxon names next to the dark bars indicate the most closely related species among the species listed on the left. Four regions, i.e., ITS, IGS, tef1, and mtSSU, showed significant inter- and intra-specific variation. 


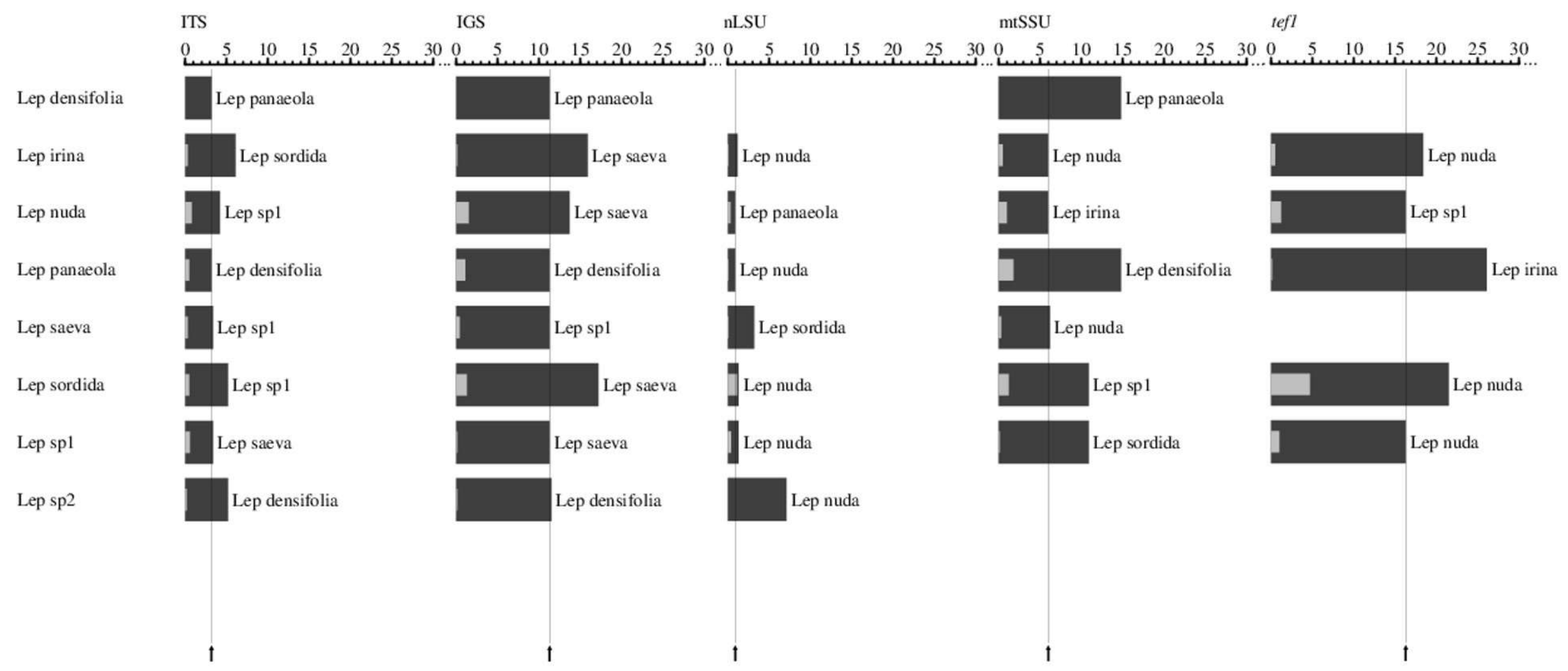




\section{Figure 2 (on next page)}

\section{Figure 2}

Frequency distributions of intra- and inter-specific Kimura-2-Parameter pairwise distances among ITS, IGS, nLSU, mtSSU, and tef1 datasets from eight Lepista spp. The black and gray bars represent the level of intra- and inter-specific variations, respectively. Three regions, i.e., ITS, IGS, and tef1, had relatively clear barcoding gaps. 
A

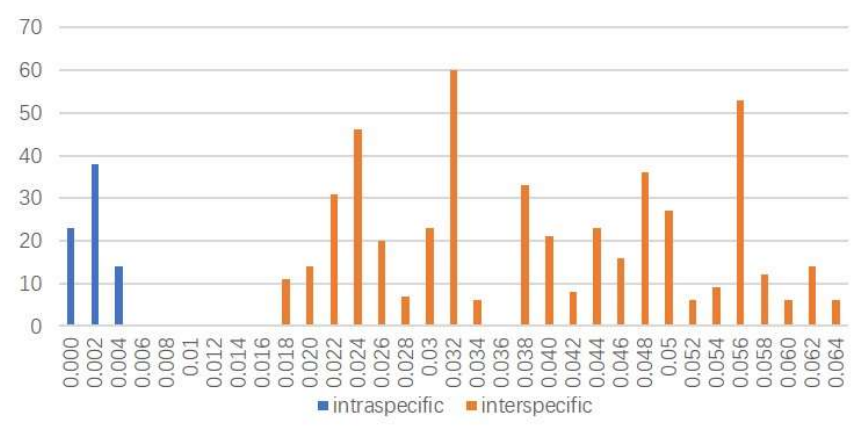

C

$n L S U$

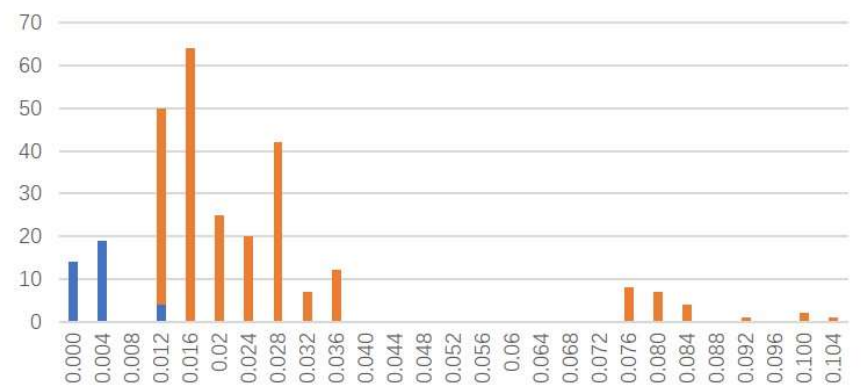

- intraspecific minterspecific
B

IGS

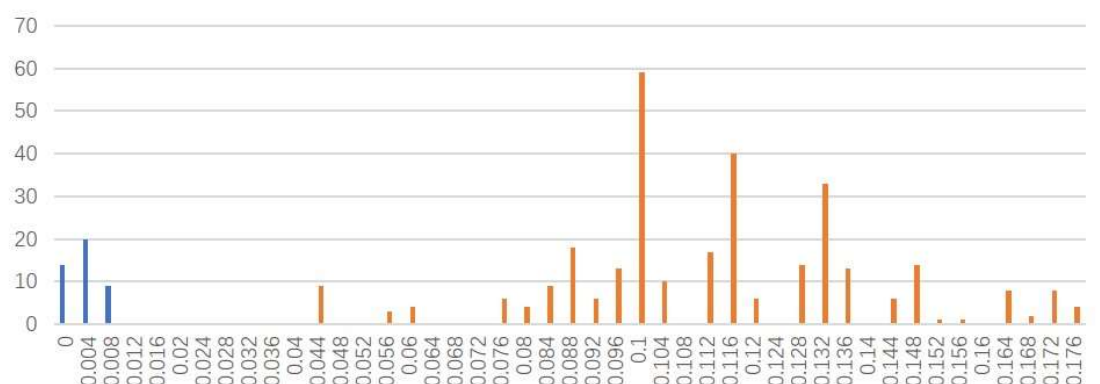

mintraspecific minterspecific

\section{D}

$\mathrm{mtSSU}$

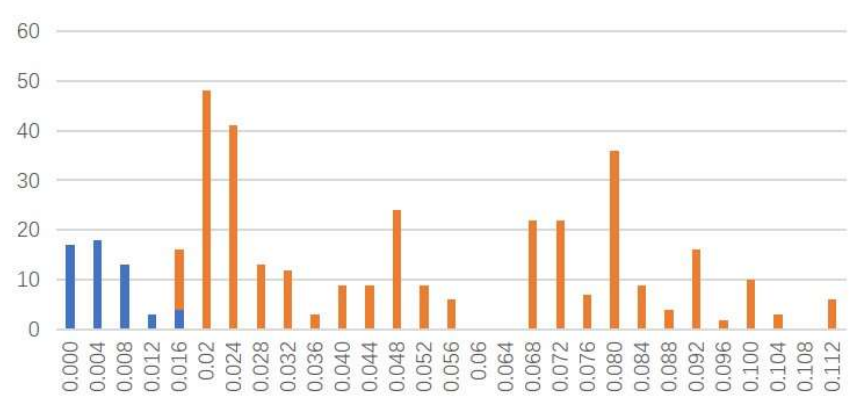

intraspecific minterspecific

\section{E}

tef1

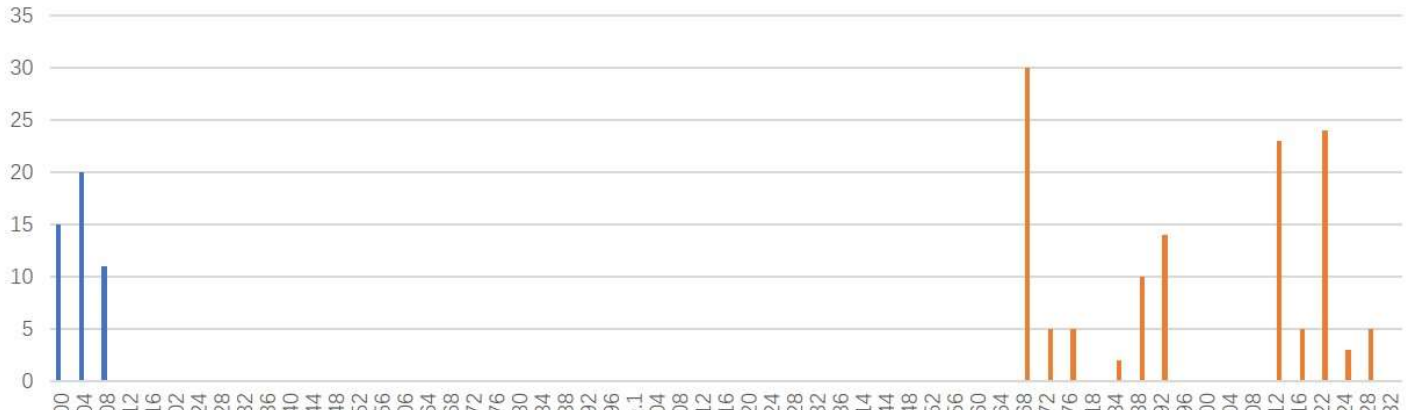

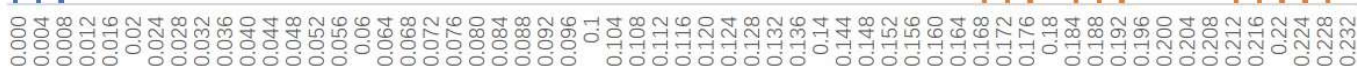

-intraspecific $=$ interspecific 


\section{Figure 3 (on next page)}

Figure 3

A neighbor-joining tree generated by analysis of ITS from eight Lepista spp. Bootstrap values $\geq 70 \%$ are shown above the relevant branches. The eight Lepista spp. are highlighted in bold. 


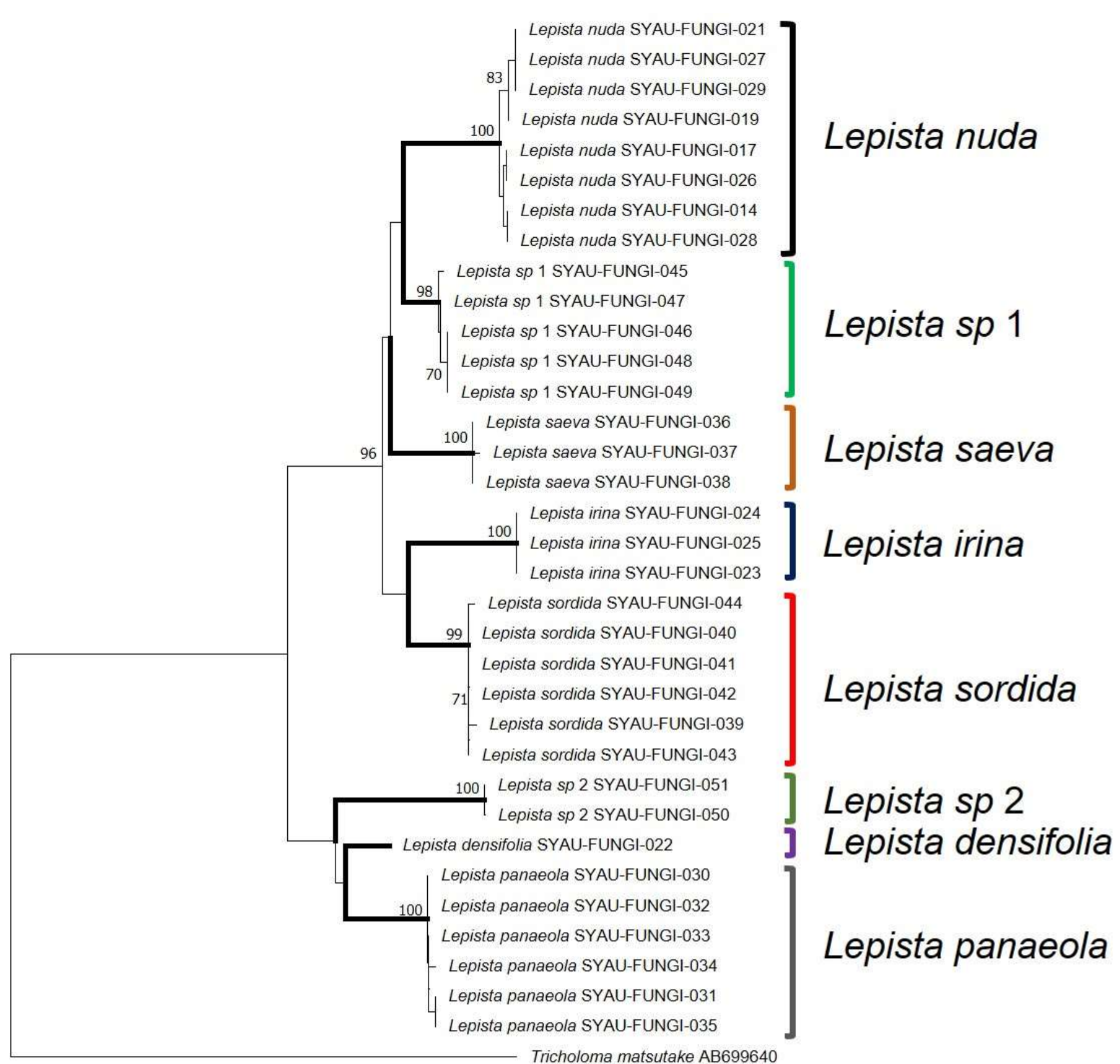




\section{Table 1 (on next page)}

Table 1

The Lepista samples used in this study. 
1 Table 1. The Lepista samples used in this study.

\begin{tabular}{|c|c|c|c|c|c|c|}
\hline Taxon & Specimen vouchera & ITS & IGSb & $n L S U^{b}$ & mtSSU & tef $1^{b}$ \\
\hline Lepista densifolia & SYAU-FUNGI-022 & MK116588 & MK389519 & - & MK389570 & - \\
\hline Lepista irina & SYAU-FUNGI-023 & MK116589 & MK389520 & MK389546 & MK389571 & MK551215 \\
\hline Lepista irina & SYAU-FUNGI-024 & MK116590 & MK389521 & MK389547 & MK389572 & MK551216 \\
\hline Lepista irina & SYAU-FUNGI-025 & MK116591 & - & MK389548 & MK389573 & - \\
\hline Lepista nuda & SYAU-FUNGI-021 & MH428843 & MK389523 & MK389549 & MK389575 & MK440311 \\
\hline Lepista nuda & SYAU-FUNGI-026 & MK116594 & - & - & - & MK440315 \\
\hline Lepista nuda & SYAU-FUNGI-017 & MH428839 & MK389524 & MK389550 & MK389576 & MK440312 \\
\hline Lepista nuda & SYAU-FUNGI-019 & MH428841 & - & MK389551 & MK389577 & MK440313 \\
\hline Lepista nuda & SYAU-FUNGI-027 & MK116593 & MK389525 & MK389552 & MK389578 & MK440314 \\
\hline Lepista nuda & SYAU-FUNGI-014 & MH428836 & MK389526 & MK389553 & MK389579 & MK440315 \\
\hline Lepista nuda & SYAU-FUNGI-028 & MK116595 & - & MK389554 & MK389580 & MK440317 \\
\hline Lepista nuda & SYAU-FUNGI-029 & MK116592 & MK389522 & - & MK389574 & MK440310 \\
\hline Lepista panaeola & SYAU-FUNGI-030 & MK116597 & MK389527 & - & MK389581 & - \\
\hline Lepista panaeola & SYAU-FUNGI-031 & MK116598 & - & - & - & - \\
\hline Lepista panaeola & SYAU-FUNGI-032 & MK116599 & MK389529 & - & MK389583 & MK551218 \\
\hline Lepista panaeola & SYAU-FUNGI-033 & MK116600 & MK389530 & MK389555 & MK389584 & - \\
\hline Lepista panaeola & SYAU-FUNGI-034 & MK116601 & MK389531 & MK389556 & MK389585 & - \\
\hline \multirow[t]{2}{*}{ Lepista panaeola } & SYAU-FUNGI-035 & MK116596 & MK389528 & MK389557 & MK389582 & \\
\hline & & & & & & MK551217 \\
\hline Lepista saeva & SYAU-FUNGI-036 & MK116602 & MK389532 & MK389558 & MK389586 & - \\
\hline Lepista saeva & SYAU-FUNGI-037 & MK116603 & MK389533 & MK389559 & MK389587 & - \\
\hline Lepista saeva & SYAU-FUNGI-038 & MK116604 & MK389534 & MK389560 & MK389588 & - \\
\hline Lepista sordida & SYAU-FUNGI-039 & MK116605 & MK389535 & MK389561 & MK389589 & MK551219 \\
\hline Lepista sordida & SYAU-FUNGI-040 & MK116606 & MK389536 & - & MK389590 & - \\
\hline Lepista sordida & SYAU-FUNGI-041 & MK116607 & MK389537 & MK389563 & MK389591 & - \\
\hline
\end{tabular}




\begin{tabular}{lllllll}
\hline Lepista sordida & SYAU-FUNGI-042 & MK116609 & MK389539 & MK389564 & MK389594 & MK551221 \\
Lepista sordida & SYAU-FUNGI-043 & MK116610 & MK389540 & MK389565 & MK389593 & MK551222 \\
Lepista sordida & SYAU-FUNGI-044 & MK116608 & MK389538 & MK389562 & MK389592 & MK551220 \\
Lepista sp 1 & SYAU-FUNGI-045 & MK116611 & - & - & MK440305 \\
Lepista sp 1 & SYAU-FUNGI-046 & MK116612 & - & MK389567 & - & MK440306 \\
Lepista sp 1 & SYAU-FUNGI-047 & MK116613 & MK389541 & MK389568 & MK389597 & MK440307 \\
Lepista sp 1 & SYAU-FUNGI-048 & MK116614 & MK389542 & MK389566 & MK389595 & MK440308 \\
Lepista sp 1 & SYAU-FUNGI-049 & MK116615 & MK389543 & - & MK389596 & MK440309 \\
Lepista sp 2 & SYAU-FUNGI-050 & MK116617 & MK389544 & - & - & - \\
Lepista sp 2 & SYAU-FUNGI-051 & MK116616 & MK389545 & MK389569 & - & - \\
\hline
\end{tabular}

2 a SYAU-FUNGI: Fungal Herbarium of Shenyang Agricultural University, Shenyang, China;

$3{ }^{b}$ GenBank accession numbers in bold indicate the sequences generated in this study. 
Table 2 (on next page)

Table 2

Primers used in this study. 
1 Table 2. Primers used in this study.

\begin{tabular}{llll}
\hline Regions & Primer & Sequence $\left(5^{\prime}\right.$-3') & Reference \\
\hline ITS & ITS5 & GGA AGT AAA AGT CGT AAC AAG G & White et al., 1990 \\
& ITS4 & TCC TCC GCT TAT TGA TAT GC & White et al., 1990 \\
IGS & CNL12 & CTG AAC GCC TCT AAG TCA G & White et al., 1990 \\
& 5SA & CAG AGT CCT ATG GCC GTG AT & White et al., 1990 \\
nLSU & LROR & ACC CGC TGA ACT TAA GC & Rehner \& Samuels, 1994 \\
& LR7 & TAC TAC CAC CAA GAT CT & Vilgalys \& Hester, 1990 \\
mtSSU & MS1 & CAG CAG TCA AGA ATA TTA GTC AAT G & White et al., 1990 \\
& MS2 & GCG GAT TAT CGA ATT AAA TAA C & White et al., 1990 \\
tef1 & tefF & TAC AAR TGY GGT GGT ATY GAC A & Morehouse et al., 2003 \\
& tefR & ACN GAC TTG ACY TCA GTR GT & Morehouse et al., 2003 \\
\hline
\end{tabular}

2 


\section{Table 3 (on next page)}

Table 3

Results of the amplification and sequencing of five regions in the genomes of eight Lepista species. 
1 Table 3. Results of the amplification and sequencing of five regions in the genomes of eight Lepista 2 species.

\begin{tabular}{|c|c|c|c|c|c|c|}
\hline Region & $\begin{array}{l}\text { Region } \\
\text { length (bp) }\end{array}$ & $\begin{array}{l}\text { Total number } \\
\text { of samples }\end{array}$ & $\begin{array}{l}\text { No. of PCR } \\
\text { successes }\end{array}$ & $\begin{array}{l}\text { PCR success } \\
\text { rate }(\%)\end{array}$ & $\begin{array}{l}\text { No. of sequencing } \\
\text { successes }\end{array}$ & $\begin{array}{l}\text { Sequencing } \\
\text { success rate (\%) }\end{array}$ \\
\hline ITS & $605-615$ & 34 & 34 & 100 & 34 & 100 \\
\hline IGS & $415-440$ & 34 & 34 & 100 & 27 & 79 \\
\hline nLSU & $934-939$ & 34 & 33 & 97 & 24 & 71 \\
\hline mtSSU & $662-740$ & 34 & 32 & 94 & 28 & 82 \\
\hline tef1 & $861-920$ & 34 & 23 & 68 & 21 & 62 \\
\hline
\end{tabular}

3 